\title{
FILÉ E MOCOTÓ: PEDAGOGIAS DOS CORPOS E HOMOSSEXUALIDADES NO SCRUFF
}

\author{
FILETE Y PEZUÑA: PEDAGOGIAS DE LOS CUERPOS Y HOMOSEXUALIDADES \\ EN EL SCRUFF
}

\author{
FILLET AND COW'S FEET: PEDAGOGIES OF BODIES AND HOMOEXUALITIES \\ IN SCRUFF
}

\author{
Danillo Mota LIMA ${ }^{1}$ \\ Edvaldo Souza COUTO
}

RESUMO: O objetivo do artigo é analisar pedagogias dos corpos e das homossexualidades produzidas por gays usuários do Scruff, ambiência digital especializada em socialização homoafetiva. O Argumento central é que esse software é um artefato cultural contemporâneo que produz pedagogias para os corpos e as homossexualidades. A metodologia utilizada foi qualitativa, de caráter descritivo e analítico. Os sujeitos foram escolhidos através da observação não participante e os dados construídos por entrevistas semiestruturadas foram analisados a partir da análise de conteúdo. Os resultados apontam que a mercantilização dos corpos constrói pedagogias culturais que privilegiam a visibilidade de homossexualidades viris na quais o músculo corporal ganha status de filé. $\mathrm{Na}$ contramão, os corpos que transgredem aos ideais dessas pedagogias culturais são percebidos como mocotó. $\mathrm{O}$ estudo conclui que as pedagogias dos corpos e homossexualidades promovidas no Scruff incitam a compreensão das homossexualidades como produtos de relações assimétricas de poder.

PALAVRAS-CHAVE: Educação e sexualidade. Tecnologia educacional. Scruff. Pedagogias culturais. Pedagogia dos corpos e homossexualidades.

RESUMEN: El objetivo del artículo es analizar pedagogías de los cuerpos y de las homosexualidades producidas por gays usuarios de Scruff, ambiente digital especializado en socialización homoafectiva. El Argumento central es que ese software es un artefacto cultural contemporáneo que produce pedagogías para los cuerpos y las homosexualidades. La metodología utilizada fue cualitativa, de carácter descriptivo y analítico. Los sujetos fueron elegidos a través de la observación no participante y los datos construidos por entrevistas semiestructuradas fueron analizados a partir del análisis de contenido. Los resultados apuntan que la mercantilización de los cuerpos construyen pedagogías culturales que privilegian la visibilidad de homosexualidades en la que el músculo corporal gana status de filete. En la contra-mano, los cuerpos que transgreden a los ideales de esas pedagogías culturales son percibidos como mocotó. El estudio concluye que las pedagogías de los cuerpos y

\footnotetext{
${ }^{1}$ Universidade Federal da Bahia (UFBA), Salvador - BA - Brasil. Doutorando em educação. Membro do grupo de pesquisa Educação, Comunicação e Tecnologia. ORCID: 〈https://orcid.org/0000-0001-8118-147X〉. E-mail: lima.danillom@gmail.com

${ }^{2}$ Universidade Federal da Bahia (UFBA), Salvador - BA - Brasil. Professor Titular da Faculdade de Educação FACED-UFBA. ORCID: <https://orcid.org/0000-0002-2648-9399>. E-mail: edvaldosouzacouto@gmail.com
} 
homosexualidades promovidas en el Scruff incitan a la comprensión de las homosexualidades como productos de relaciones asimétricas de poder.

PALABRAS CLAVE: Educación y sexualidade. Tecnología educativa. Scruff. Pedagogías culturales. Pedagogía de los cuerpos y homosexualidades.

ABSTRACT: The article aims to analyze bodies and homosexuals pedagogies produced by gay users of the Scruff apps, digital ambience specializing in homoaffective socialization. The central argument is that this software is a contemporary cultural artifact that produces pedagogies for bodies and homosexuality. The methodology used was qualitative, descriptive and analytical. The subjects were chosen through non-participant observation and the data constructed by semi-structured interviews were studied from the content analysis. The results indicate that the commercialization of the bodies constructs cultural pedagogies, which favor the visibility of manly homosexuals, in which the body muscle gains fillet status. On the other hand, bodies that transgress the ideals of these cultural pedagogies are perceived as cow's feet. The study concludes that the pedagogies of the bodies and homosexuals promoted in the Scruff incite the understanding of homosexuality as products of asymmetric relations of power.

KEYWORDS: Education and sexuality. Educational technology. Scruff. Cultural pedagogies. Pedagogy of bodies and homosexualities.

\section{Introdução}

Esse estudo apresenta resultados de uma pesquisa que teve como tema central as construções e educações dos corpos e das homossexualidades no Scruff, ambiência digital especializada em socialização homoafetiva. O objetivo foi analisar as pedagogias dos corpos e homossexualidades produzidas por gays que transitam pelo aplicativo digital. $\mathrm{O}$ argumento principal é que em tempos ciberculturais, aplicativos como o Scruff ganham caráter de Pedagogia Cultural, pois constroem processos de ensino e aprendizagem sobre comportamentos e valores considerados desejáveis para os que se conectam a essa rede. Para fundamentar esse argumento utilizamos como aporte teórico os Estudos Culturais em Educação, Estudos de Gêneros e Sexualidades e estudos da Cibercultura.

$\mathrm{O}$ artigo está dividido em quatro seções. A primeira apresenta a abordagem e o tipo de pesquisa, a escolha dos sujeitos e os procedimentos para construção e análise dos dados. A segunda faz um diálogo entre os Estudos Culturais em Educação, os Estudos de Gêneros e Sexualidades e os estudos da Cibercultura para discutir o caráter pedagógico do Scruff. A terceira seção analisa pedagogias dos corpos e homossexualidades produzidas pelos sujeitos deste estudo. O resultado da análise aponta a mercantilização das relações gays se assemelham 
às transações de compra e venda em um mercado de corpos e desejos. Nesse, o músculo é o centro das interações e negociações, pois, através dele os usuários criam formas detalhadas de gerenciamento do corpo e de exibição do desejo homoafetivo.

Na quarta seção concluímos que o Scruff, ao proporcionar uma visibilidade democrática dos corpos e das homossexualidades, revela as homossexualidades como produtos de relações assimétricas de poder. Nelas, os comportamentos são vigiados, de forma intensiva e extensiva, em termos de sua relação com o corpo e com a sexualidade, a fim de produzir territórios de existência gays considerados desejáveis. Nesse sentido, corpos e homossexualidades afeminadas, gordas, velhas e negras ocupam um lugar importante de resistência política, pois problematizam as normatividades dos corpos e das sexualidades.

\section{Metodologia da pesquisa}

O método de pesquisa usado foi o qualitativo, de caráter descritivo e analítico (MINAYO; DESLANDES; GOMES, 2012). Utilizamos as técnicas de observação não participante e da entrevista semiestruturada para a construção dos dados. Essa opção metodológica foca nas experiências sociais e nas produções culturais pois trata o conhecimento como um processo socialmente construído pelos sujeitos nas suas interações cotidianas. Desse modo, é preocupação dessa abordagem metodológica a compreensão das relações individuais e grupais através da observação, do registro e da análise dos fatos e fenômenos (variáveis) produzidos.

Os sujeitos da pesquisa foram escolhidos através da observação não participante, durante três meses, no Scruff. O primeiro recorte foi estabelecido a partir da frequência de uso do aplicativo. Dentre os 100 perfis disponibilizados gratuitamente, foram mapeados 26 perfis que mais interagiram, seja mudando o texto de apresentação ou a foto ou o nome de usuário. Desses, 7 aceitaram fazer entrevista para a pesquisa. Na tabela abaixo encontramos os pseudônimos, idade e nível de escolaridade dos sujeitos: 
Tabela 1 - Caracterização dos sujeitos da pesquisa. Maio/2016

\begin{tabular}{l|l|l|} 
Pseudônimo & Idade & Nível de Escolaridade \\
\hline Fruta Gogoia & 34 & Superior completo \\
\hline Neide & 27 & Mestre \\
\hline Mistica & 26 & Mestre \\
\hline Greta & 23 & Superior \\
\hline Teresa Shantily & 22 & Superior \\
\hline Beija-Flor & 28 & Superior \\
\hline Abighail & 19 & Ensino Médio \\
\hline
\end{tabular}

Fonte: Autores

Com os sujeitos escolhidos foi realizada entrevista semiestruturada. Esse procedimento de construção dos dados tornou-se viável para a pesquisa, vez que favorece não só a descrição dos fenômenos sociais, mas também sua explicação e a compreensão de sua totalidade. Alguns sujeitos preferiram responder a entrevista através do próprio Scruff, outros, através do Facebook.

Os dados produzidos por meio da observação não participante e da entrevista semiestruturada foram organizados e analisados sob a ótica da Técnica de Análise de Conteúdo (AC), seguindo as fases propostas por Bardin (2011): pré-análise, exploração do material e tratamento dos dados, inferência e interpretação.

\section{Corpos e homossexualidades no Scruff}

As construções sociais do sujeito experimentam uma transformação vertiginosa nas últimas décadas. Elas têm suas raízes no início do século XX, quando a mídia e a cultura de massa começaram a ocupar o espaço que, até então, era ocupado pelas Universidades e pela cultura erudita. Com a industrialização da cultura, os diferentes artefatos culturais como o cinema, a televisão, as revistas, a literatura, a moda, a publicidade etc. ganham caráter de 
instâncias pedagógicas pois, passaram a produzir ou transformar a experiência que as pessoas têm de si mesmas e dos outros. (GIROUX, 2018).

O campo dos Estudos Culturais na área da Educação tem possibilitado a construção de um espaço intelectual empenhado a investigar esses lugares de produção dos sujeitos pois, ao salientar as conexões entre Educação e Comunicação, destacam o caráter pedagógico dos artefatos e objetos de cultura. Os teóricos desse campo compreendem a pedagogia como um espaço de construção, uma prática cultural cujo objetivo é estruturar modos de ser sujeito (GIROUX, 2018; ANDRADE; COSTA, 2017).

Atualmente, as tecnologias digitais inauguram um novo modo de ser na nossa sociedade. Aparelhos tecnológicos conectados à internet incitam a exibição, a participação e a criação em rede. A cibercultura e o ciberespaço proporcionam o trânsito de conhecimentos e potencialidades que manifestam e alteram os modos de ser e estar no mundo. Nesse sentido, aplicativos de socialização homoafetiva, como o Scruff, configuram-se como artefatos culturais contemporâneos que produzem pedagogias culturais para os corpos e as homossexualidades (LIMA; COUTO, 2018; MILLER, 2018).

O Scruff faz parte de um amplo e crescente conjunto de softwares digitais especializados em relacionamentos afetivo-sexuais para a comunidade gay. Esses softwares utilizam o GPS e as informações divulgadas por seus usuários (fotos, idade, peso, altura etc.) para criar uma comunidade gay virtual. Disponibilizado no mercado em 2010, o aplicativo foi, a princípio, pensado para ser uma comunidade de gays ursos, mas, devido a sua compatibilidade com os principais sistemas operacionais (Android, Windows Phone e IOS) o número de usuários aumentou, ultrapassando os 10 milhões.

No Scruff é mostrado uma grade com 100 usuários que se encontram geograficamente perto. Além disso, diferente dos outros aplicativos do mercado, permite que um usuário pesquise por outros em localidades diferentes: um usuário do Brasil pode filtrar sua grade para mostrar apenas usuário dos Estados Unidos, França ou Japão, por exemplo. Outras opções como compartilhamento de álbuns e acesso ilimitado a todos os usuários só são permitidas com a assinatura da versão Pro, no valor de US\$ 12,99 por mês. 
Em tempos ciberculturais, aplicativos como o Scruff ganham caráter de Pedagogia Cultural pois constroem processos de ensino e aprendizagem através de pedagogias estruturais que ensinam procedimentos, comportamentos e valores considerados desejáveis para os que se conectam a essa rede. As pedagogias culturais são criadas por meio de estruturas de pensamentos, conjunto de ideias e de práticas sociais que circulam na rede. Nesse contexto, o Scruff é entendido como um espaço social onde múltiplos sujeitos se encontram. Os gays, com suas idiossincrasias, caminham nessa ambiência digital produzindo modos de se relacionar, de ser e estar, aparecer e se comportar (GIROUX, 2018; MILLER, 2018; LIMA; COUTO, 2018; COUTO, 2015).

As pedagogias culturais dos corpos e das homossexualidades ocorrem através de um conjunto de métodos, procedimentos e técnicas que garantem a adaptação de conteúdos informativos e educativos sobre os corpos, os sexos, os comportamentos, os prazeres e as linguagens. Elas "mobilizam aparatos e dispositivos, refazem ou repetem dizeres, modos, movimentos considerados como legítimos por normas de nossa cultura”. (LOURO, 2017, p. 74).

Dessa maneira, criam um processo de identificação dos sujeitos através dos gestos, das formas como se apresentam corporalmente, comportamentos adotados e formas com que se expressam, operando classificações, ordenações e hierarquias dos corpos e homossexualidades. Tais processos também estão presente em ambientes escolares, nos quais privilegiam pedagogias culturais de masculinidades viris como norteadora dos corpos dos estudantes (GALET; SEFFNER, 2016).

Nessa perspectiva, as pedagogias que circulam no aplicativo são uma forma de produção política e cultural profundamente influenciada na construção das subjetividades e relações sociais da comunidade gay. As interações produzidas nesse aplicativo geram instâncias pedagógicas capazes de produzir saberes e valores acerca dos corpos e das sexualidades, fabricam representações e identidades, constituem certas relações de poder, ensinam modos de ser homem, formas diversas de viver as homossexualidades. Nesse caminho vertiginoso, desejo e espetáculo, tecnologias e corpos, atração e repulsa, sexualidade e mercado, online e offline se 
cruzam em rede para colocar ao toque do dedo, através de softwares em telas, renovadas formas de viver os corpos e homossexualidades dilatadas em nossa sociedade pós-moderna (LIMA; COUTO, 2018; MILLER, 2018; COUTO, 2015).

\section{Filé e mocotó: pedagogias dos corpos e das homossexualidades no Scruff}

Os sujeitos, neste estudo, relataram suas experiências no Scruff, especialmente sobre as construções dos corpos, apontando comportamentos e usos exigidos como fundamentais para vivenciarem suas sexualidades. Elas também descreveram a dinâmica de interação dentro do aplicativo, profundamente marcada por uma homofobia internalizada, sustentada por um processo de hierarquização dos corpos, baseada em aparências físicas que remetem ao ideal atribuído ao homem viril (MILLER, 2018; LIMA; COUTO, 2018);

Por ser um ambiente em que vigora a procura pelo sexo rápido, todo o corpo é pensado em forma de exibição, incluindo os órgãos sexuais. Como relata Greta: "[A Nudes] é importante na construção do corpo, porque foi feita pra ser exibida. Em um momento mais íntimo, mas vai ser exibida.".

Nesse sentido, o corpo é construído como um espetáculo a ser visto, pois é através da exposição e das performances imagéticas que se expõe o desejo por outros corpos e homossexualidades. Dessa maneira, o corpo funciona ao mesmo tempo como o promotor da mercadoria e a mercadoria que promove (MILLER, 2018; LIMA; COUTO, 2018). Neste ciclo, a aquisição do produto, sua satisfação e a sua saturação são rápidas, como se pode observar nas seguintes unidades de análise:

É uma construção de sedução. Você seduz através do seu perfil, do seu corpo, da sua foto, sabe? Aí, parece uma prateleira com vários itens, com vários modelos que você vai lá, escolhe o que você quer pegar (Neide).

Pela bios parece que é carne de açougue. A gente abre, escolhe e ver o que dá (Beija-Flor).

Nas falas das entrevistadas, percebe-se a mercantilização das relações interpessoais que se assemelham às transações de compra e venda em um mercado de corpos e desejos. Nesse, o músculo é o centro das interações e negociações. Através dele, os usuários criam formas 
detalhadas de gerenciamento do corpo e de exibição do desejo homoafetivo, como demonstram as unidades de análise:

Coloco a foto de um cara legal, com o corpo mais malhado, com um bermudão, sem camisa ou de camiseta. Esse é o segredo, saber escolher a foto na medida, tem que ser malhado, mas não exagerado, sabe? Pq eles interagem mais rápido, mandam foto de rosto com mais facilidade. (Fruta Gogoia)

Geralmente, quando quero sexo, eu uso as gírias "firmeza", "cara", "fera", "boto fe", tem que fazer a linha mais dura e colocar uma foto com um corpo mais malhadinho. (Mistica)

Tiro fotos de ângulos que fazem parecer que sou mais forte, com uma postura um pouco mais máscula. (Teresa shantily)

O corpo malhado é percebido como viril e torna-se referência e ideal simbólico para os outros corpos e homossexualidades. A partir dele os outros serão definidos e denominados em um processo de divisões e atribuições de rótulos, que separa de forma violenta e discriminatória outras expressões de corpos e homossexualidades (LIMA; COUTO, 2018; MILLER, 2018).

Os termos filé e mocotó são utilizados pelas entrevistadas para adjetivar as mercadorias que circulam pelo Scruff. Segundo Greta, o filé "é o corpo branco, ou o mais próximo do branco, o corpo forte, o corpo duro, cheio de músculo: que não é afeminado, que não se parece com o da mulher". Em contrapartida, "o mocotó é o corpo afeminado, magro demais, gordo demais, velho, assumido demais." Dessa forma, os discursos sobre a masculinidades viris conduzem a produção e a valorização das homossexualidades discretas, àquela que não acusam o sujeito e garantem o seu sigilo (LIMA; COUTO, 2018; MILLER,2018; LOURO, 2017).

No Scruff, o processo avaliativo dos corpos e das homossexualidades efetua-se a partir de graus de estranheza. Segundo as entrevistadas, o corpo afeminado é o mais estranho, seguido dos velhos, gordos e negros, como demonstram as unidades de análise:

Quanto mais minorias é mais estranha: magra demais, Gorda, HIV+, Surubeira, Geek (Beija-flor).

Dou block em perfis que vem escrito, logo de cara, que é afeminado, que é passivo, que é submisso (Neide).

Se você, além de afeminada, for preta e pobre, você não existe no Scruff (Abigail) 
As construções dessas pedagogias culturais geram um certo processo de ocultamento dos corpos que se distanciam do músculo e dos ideais de masculinidade viris. O ocultamento pode ser percebido nas escolhas das fotografias para construção corporal. Em ambiências como o Scruff, a avaliação dos corpos se amplifica ainda mais, pois, por ser um software leve e compatível com todos os sistemas operacionais disponíveis no mercado, possibilita o acesso a partir de Smartphones de modelos simples, com baixo custo financeiro. Beija-Flor descreve, com um olhar bastante estigmatizador, os usuários do Scruff:

O Scruff era para ursos, quando foi lançado nos EUA, mas, aqui no Brasil, ele se popularizou demais. Hoje você vê que as bixinhas quá, quá, as afeminadas, estão todas no Scruff. O GRINDR como exige um smartphone mais potente o público é mais elitizado.

Nesse contexto, o rechaço e mascaramento desses corpos aparentam ter por finalidade extingui-los ou impedir que as outras homossexualidades os conheçam. Nesse sentido, corpos e homossexualidades dissidentes, como os afeminados, pretos, velhos e gordos, são considerados mocotó por subverterem modelos idealizados das vivências dos corpos e sexualidades.

\section{Considerações finais}

Esse estudo nos permitiu concluir que, ao proporcionar a visibilidade democrática dos corpos e das homossexualidades, o Scruff dá visibilidade as homossexualidades como produtos de relações assimétricas de poder. O ocultamento e rechaço dos corpos afeminados, velhos, gordos e negros revelam que as pedagogias dos corpos e das homossexualidades, apesar de serem produzidas em um ambiente que possibilita e potencializa a vivência de uma sexualidade considerada "dissidente", reproduzem velhas hierarquizações dos corpos e das homossexualidades. Nelas, os comportamentos são vigiados, de forma intensiva e extensiva, em termos de sua relação com o corpo e com a sexualidade, a fim de produzir territórios de existência gays considerados desejáveis. Nesse sentido, corpos e homossexualidades afeminadas, gordas, velhas e negras ocupam um lugar importante de resistência política, pois problematizam as normatividades dos corpos e das sexualidades. 
Com esse estudo concluímos também que os corpos e as homossexualidades que transgredem as fronteiras do músculo e da virilidade possibilitam questões significativas e políticas sobre os corpos e as homossexualidades, pois revelam seu caráter político e pedagógico. No Scruff, essas vivências transgressivas desterritorializam os corpos e as homossexualidades, não os subordinando aos modelos idealizados que se autodeterminam e, tampouco, às pedagogias culturais tradicionais dos corpos e das homossexualidades. Dessa forma os corpos e as homossexualidades afeminadas podem gerar novas possibilidades na desorganização de fronteiras entre o masculino e o feminino, assim como no estabelecimento de outras combinações além das masculinidades e homossexualidades viris.

AGRADECIMENTOS: À FAPESP- Fundação de Amparo à Pesquisa do Estado da Bahia pela bolsa de fomento

\section{REFERÊNCIAS}

ANDRADE, Paula.; COSTA, Marisa. Nos rastros do conceito de pedagogias culturais: Invenção, disseminação e uso. Educ. ver, v. 33, jun., 2017. Disponível em: www.scielo.br/scielo.php?pid=S0102-46982017000100118\&script=sci_arttex. Acesso em: 15 out. 2018.

BARDIN, Lawrence. Análise de conteúdo. Lisboa, 2011.

COUTO, Edvaldo. Vida privada na esfera pública: narrativas de corpos e sexualidades nas redes sociais digitais. Revista entreideias: educação, cultura e sociedade, Salvador, v. 4, n. 1, 2015. Disponível em: https://portalseer.ufba.br/index.php/entreideias/issue/view/995. Acesso em: 04 jun. 2017.

GALET, Carmen.; SEFFNER, Fernando. Dois Olhares sobre masculinidades no ambiente escolar. Rev. Ibero-Americana de Estudos em Educação, Araraquara, v. 11, n. 2, abr./jun., 2016. Disponível em:

https://periodicos.fclar.unesp.br/iberoamericana/article/view/8322/5826. Acesso em: 04 abr. 2017.

GIROUX, Henry. Education in unsettling times: public intellectual and promise of cultural studies. In: Power/knowledge/pedagogy: the meaning of democratic education in unselttling times. Taylor e Francys Group Online, 2018. Disponível em: //www.taylorfrancis.com/books/e/9780429966613/chapters/10.4324\%2F9780429498060-2. Acesso em: 17 ou.t 2018.

LÉVY, Pierre. Cyberculture. Paris, Éditions Odile Jacob, 1997. 
LIMA, Danillo.; COUTO, Edvaldo. Pedagogias de masculinidades e estéticas monstras no Scruff. In: RIBEIRO, Paula; MAGALHÃES, Joanalira.; SEFFNER, Fernando.; VILAÇA, Teresa. Corpo, gênero e sexualidade: resistências e ocup(ações) nos espaços de educação. Rio Grande, Editora da FURG, 2018.

LOURO, Guacira Lopes. Flor de Açafrão: takes, cuts, close-ups. Rio de Janeiro: Editora Autêntica, 2017.

MILLER, Brandon. Textually Presenting Masculinity and the Body on Mobile Dating Apps for Men Who Have Sex With Men. The Journal of Men's Studies, v. 26, n. 3, 2018.

Disponível em:

sagepub.com/doi/abs/10.1177/1060826518773417?casa_token=Q6TbYRf03MQAA\%3AuIp7 kafJC0STYcmRgDJXEduUzY3W3EAZFLzqCyFUx39K1astHaOac169WA5OgiDx7a5b3W6 0BEPH_hs\&. Acesso em: 17 out. 2018.

MINAYO, Maria C.; DELANDES, Suely F.; GOMES, Romeu. Pesquisa social: teoria, método e criatividade. Petrópolis: Vozes, 2012.

\section{Como citar este artigo:}

MOTA, Danillo Lima; COUTO, Edvaldo Souza. Filé e Mocotó: Pedagogia dos corpos e homossexualidades no Scruff. Revista Ibero-Americana de Estudos em Educação, Araraquara, v. 14, n. 3, p. 1100-1110, jul./set., 2019. e-ISSN: 1982-5587. DOI: 10.21723/riaee.v14i3.11907

Data de Submissão: $15 / 11 / 2018$

Revisões requeridas: 18/01/2019

Aceite em: 21/03/2019

Publicado em: 10/05/2019 